\title{
Diosmetin inhibits the metastasis of hepatocellular carcinoma cells by downregulating the expression levels of MMP-2 and MMP-9
}

\author{
JIE LIU* ${ }^{*}$ XIAOJUN WEN* ${ }^{*}$ BIN LIU, QINGYU ZHANG, JINGJING ZHANG, HUILAI MIAO and RUNZHI ZHU \\ Laboratory of Hepatobiliary Surgery, Affiliated Hospital of Guangdong Medical University, \\ Zhanjiang Key Laboratory of Hepatobiliary Diseases, Zhanjiang, Guangdong 524001, P.R. China
}

Received March 25, 2015; Accepted December 23, 2015

DOI: $10.3892 / \mathrm{mmr} .2016 .4872$

\begin{abstract}
Hepatocellular carcinoma (HCC) is one of the most malignant types of tumor worldwide with a high rate of mortality. Diosmetin (DIOS) exhibits various activities, including anticancer activities. However, the role of DIOS in the metastasis of HCC, and its underlying molecular mechanism, remain to be fully elucidated. In the present study, the antimetastatic effects of DIOS were investigated in SK-HEP-1 and MHcc97H HCC cell lines. Cell proliferation, wound healing, motility, invasion and adhesion capacities were examined to evaluate the inhibitory effect of DIOS on the metastasis of HCC cells. Cell viability was detected using an MTT assay in order to verify the inhibitory effect of DIOS on the proliferation of HCC cells. Cell migration was assessed using would healing and motility assays in order to verify the inhibitory effect of DIOS on the migration of HCC cells. Cell invasion and adhesion assays were performed in order to verify the inhibitory effect of DIOS on the invasion and adhesion of HCC cells. Matrix metalloproteinase (MMP)-2/9, proteins of the mitogen-activated protein kinase (MAPK) pathway (c-Jun N-terminal kinase, extracellular signal-regulated kinase and p38 MAPK) and protein kinase $C-\delta$ were detected in order to verify the potential molecular mechanisms of DIOS in the inhibition of the metastasis of HCC cells. DIOS was observed to inhibit the metastasis of SK-HEP-1 and MHcc97H cells by downregulating the expression of MMP-2/9 via the PKC/MAPK/MMP pathways. DIOS also inhibited the migration and invasion of the HCC cells, and may serve as a potential candidate agent for the prevention of HCC metastasis.
\end{abstract}

Correspondence to: Mr. Huilai Miao or Mr. Runzhi Zhu, Laboratory of Hepatobiliary Surgery, Affiliated Hospital of Guangdong Medical University, Zhanjiang Key Laboratory of Hepatobiliary Diseases, 57 South Renmin Road, Zhanjiang, Guangdong 524001, P.R. China

E-mail: hepatolab@163.com

E-mail: runzhizhu1978@163.com

*Contributed equally

Key words: diosmetin, hepatocellular carcinoma, metastasis, matrix metalloproteinases, mitogen-activated protein kinase

\section{Introduction}

Hepatocellular carcinoma (HCC) is one of the most malignant types of tumor worldwide, and is the third most common cause of cancer-associated mortality $(1,2)$. Due to the limitations of surgery and liver transplantation, including inoperable tumors and tissue matching, chemotherapy remains the major treatment method for HCC (3). Previous studies have shown that the metastasis of cancer cells involves complex processes, in which the cancer cells invade the surrounding tissue, enter the bloodstream or lymph circulation, and form new tumors $(4,5)$. The degradation of the extracellular matrix (ECM) is crucial in cancer cell migration and invasion, and a series of proteinases are involved in this process, including matrix metalloproteinases (MMPs) (6).

Diosmetin (3',5,7-trihydroxy-4'-methoxyflavone $\left(\mathrm{C}_{16} \mathrm{H}_{12} \mathrm{O}_{6}\right.$; DIOS; Fig. 1) is found in the legume, Acacia farnesiana, and in the leaves of Olea europaea L., and is the aglycone of the lavonoid glycoside, diosmin (7). It has been confirmed that DIOS has several medicinal properties, including antibacterial (8), antimicrobial (9), anti-inflammatory (10) and antioxidant (11) activities. It has also been confirmed that DIOS exerts cytostatic effects in MDA-MB 468 cells, a breast cancer cell line, by inducing cell cycle arrest (12). However, the effect of DIOS on the invasion and metastasis of HCC cells, and the antimetastatic mechanisms of DIOS remain to be fully elucidated. The aim of the present study was to investigate the anti-metastasis effect of DIOS on HCC cells and the underlying mechanisms.

\section{Materials and methods}

Reagents and antibodies. Diosmetin (Sigma-Aldrich, St. Louis, MO, USA) was dissolved in dimethyl sulfoxide (DMSO; MP Biomedicals, Santa Ana, CA, USA) at a stock solution concentration of $5 \mathrm{mg} / \mathrm{ml}$, and was diluted as a working fluid for cell culture medium prior to use. Concentrations of DIOS used in the MTT assay were $0,2,5,10,20,30,40,50$ and $100 \mu \mathrm{g} / \mathrm{ml}$; whereas $0,10,20$ and $40 \mu \mathrm{g} / \mathrm{ml}$ DIOS was used in the other assays. The 3-(4, 5-dimethylthiazol-2-yl)-2,5-diphenyltetrazolium bromide (MTT) was purchased from Sigma-Aldrich. Matrigel was purchased from BD Biosciences (Franklin Lakes, NJ, USA). SYBR Premix Ex Taq ${ }^{\mathrm{TM}}$ II kits were purchased from Takara Bio, Inc. (Shiga, Japan). Antibodies against GAPDH, MMP-2, MMP-9, c-Jun N-terminal kinase (JNK), phosphorylated 
(p)-JNK, extracellular signal-regulated kinase (ERK)1/2, p-ERK1/2 and protein kinase $C(\mathrm{PKC})-\delta$ were purchased from Cell Signal Technology, Inc. (Boston, MA, USA). Horseradish peroxidase-(HRP) conjugated goat anti-rabbit immunoglobulin G secondary antibody was purchased from EarthOx Life Sciences (Millibrae, CA, USA).

Cell culture. The MHcc97H and SK-HEP-1 HCC cell lines were purchased from the Shanghai Cell Bank of Chinese Academy of Science (Shanghai, China). The cells were maintained in Dulbecco's modified Eagle's medium (DMEM; Thermo Fisher Scientific, Inc., Waltham, MA, USA), supplemented with $10 \%$ fetal bovine serum (FBS; Gibco; Thermo Fisher Scientific, Inc.), and were cultured in a $37^{\circ} \mathrm{C}, 5 \% \mathrm{CO}_{2}$ incubator. The cells were passaged at $90 \%$ confluence.

Cell proliferation assay. Cell proliferation rates were detected using an MTT assay. The cells were seeded into a 96-well plate at a density of $10^{4}$ per well in $100 \mu \mathrm{l}$ culture medium. Following $24 \mathrm{~h}$ adhesive culture at $37^{\circ} \mathrm{C}$, the medium was removed and replaced with the same volume of medium containing either 2, 5, 10, 20, 30, 40, 50 and $100 \mu \mathrm{g} / \mathrm{ml}$ DIOS, with cells cultured in normal medium as a control group. After $24 \mathrm{~h}$ incubation at $37^{\circ} \mathrm{C}, 20 \mu \mathrm{l}$ MTT stock solution, at a concentration of $5 \mathrm{mg} / \mathrm{ml}$, was added to each well of the plate and, following $3 \mathrm{~h}$ incubation at $37^{\circ} \mathrm{C}$, the medium was removed gently and $200 \mu 1$ DMSO was added per well. The absorbance was then detected using a microplate reader (PerkinElmer, Waltham, MA, USA) at a wavelength of $570 \mathrm{~nm}$. These experiments were performed independently in triplicate.

Wound healing assay. Migration capacities of the HCC cell lines under DIOS treatment were detected using a wound healing assay. The cells were seeded in a 24 -well plate in DMEM containing 10\% FBS for $24 \mathrm{~h}$, when the cells were at $100 \%$ confluence. A wound was then created in the cell layer using a pipette tip. Following washing twice with phosphate-buffered saline (PBS) to remove cellular debris, the cells were cultured in the absence or presence of 5 , 10 or $20 \mu \mathrm{g} / \mathrm{ml}$ DIOS in DMEM containing 1\% FBS for $24 \mathrm{~h}$ at $37^{\circ} \mathrm{C}$. The cells were observed under a microscope, and images of the cells were captured when the wound was created and at $24 \mathrm{~h}$-post wounding. Migration rates were calculated using the following formula: Migration rate $=[$ width of $(0-24 \mathrm{~h}) /$ width of $24 \mathrm{~h}] \times 100 \%$.The experiments were performed in triplicate independently.

Cell motility assay. Cells were seeded in Transwell chambers, comprising porous polycarbonate membranes with a pore size of $8.0 \mu \mathrm{m}$ (Corning, Corning, NY, USA), at a concentration of $1 \times 10^{5}$ cells/chamber in the absence or presence of $100 \mu \mathrm{l} 5,10$ or $20 \mu \mathrm{g} / \mathrm{ml}$ DIOS in DMEM. Chambers were then fitted into the lower wells of the Transwell system in a 24-well plate (BD Biosciences), which contained $600 \mu \mathrm{l}$ DMEM containing 10\% FBS. Following incubation for $24 \mathrm{~h}$ at $37^{\circ} \mathrm{C}$, the cells that passed through the membrane were fixed in $70 \%$ ethanol, and then stained with $0.1 \%$ crystal violet (Amresco, Solon, OH, USA). The cells were observed under a an Olympus IX70 microscope (Olympus Corporation, Tokyo,

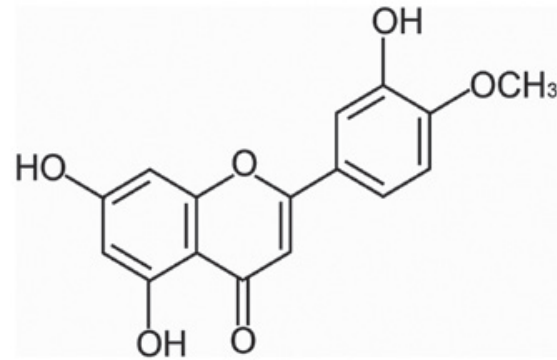

Figure 1. Chemical structure of Diosmetin.

Japan) and counted in the last four fields of each group. Three independent experiments were performed in triplicate.

Cell invasion assay. The methods used for the cell invasion assay were similar to those of the cell motility assay, with the exception that each Transwell chamber was pretreated with Matrigel (1:10 diluted in DMEM), of which $100 \mu \mathrm{l}$ per chamber was added. The chambers were placed into a $37^{\circ} \mathrm{C}$ incubator for $2 \mathrm{~h}$ prior to use.

Cell adhesion assay. A cell adhesion assay were performed, as previously reported (3). Briefly, each well of a 96-well plate was coated with $10 \mu \mathrm{l}$ fibronectin (R\&D systems, Minneapolis, MN, USA), and the plates were placed in to a $37^{\circ} \mathrm{C}$ incubator for 2 days. The plates were washed twice with DMEM prior to use. The cells were pretreated with 5,10 or $20 \mu \mathrm{g} / \mathrm{ml}$ DIOS for $24 \mathrm{~h}$ at $37^{\circ} \mathrm{C}$, following which the cells were harvested and seeded into the 96-well plate coated with fibreonectin, at a density of $5 \times 10^{5}$ cells $/ \mathrm{ml}$ for $100 \mu \mathrm{l}$. After $2 \mathrm{~h}$, the medium and non-adhesive cells were removed, and the adhered cells were detected using an MTT assay.

Reverse transcription-quantitative polymerase chain reaction (RT-qPCR) analysis. The expression levels of the MMPs and tissue inhibitors of MMPs were detected using RT-qPCR. The total RNA of the cells were extracted using TRIzol reagent (Invitrogen; Thermo Fisher Scientific, Inc.), and reverse transcription to cDNA was performed using a PrimeScript ${ }^{\mathrm{TM}}$ RT reagent kit with gDNA Eraser (Takara Bio, Inc.). qPCR reactions were performed using a Roche LightCycler 480 II (Roche Diagnostics, Basel, Switzerland), according to the instructions of the SYBR ${ }^{\circledast}$ Premix Ex Taq ${ }^{\mathrm{TM}}$ II, ROX plus (Takara Bio, Inc.). Specific primers for each gene were designed as follows: GAPDH, forward 5'-TGCACCACCAAC TGCTTAG-3' and reverse 5'-AGTAGAGGCAGGGATGAT GTTC-3' as internal control; MMP2, forward 5'-CCACAG GAGGAGAAGGCTGT-3' and reverse 5'-CTCCAGTTA AAGGCGGCATC-3'; and MMP9, forward 5'-ACGACGTCT TCCAGTACCGA-3' and reverse 5'-TTGGTCCACCTGGTT CAACT-3'. Thermal cycling conditions were $95^{\circ} \mathrm{C}$ for $30 \mathrm{sec}$, followed by 40 cycles of amplification at $95^{\circ} \mathrm{C}$ for $5 \mathrm{sec}$ and $60^{\circ} \mathrm{C}$ for $30 \mathrm{sec}$. Data are representative of three independent assays and expression levels were calculated according to the $\Delta \Delta \mathrm{Cq}$ method and expressed as $2^{-\Delta \Delta \mathrm{Cq}}(13)$.

Western blot analysis. The protein expression levels of MMP-2, MMP-9, JNK, p-JNK, ERK1/2, p-ERK1/2 and PKC- $\delta$ were 
A

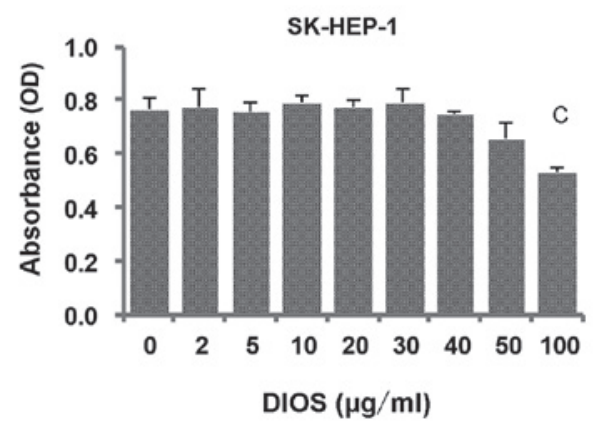

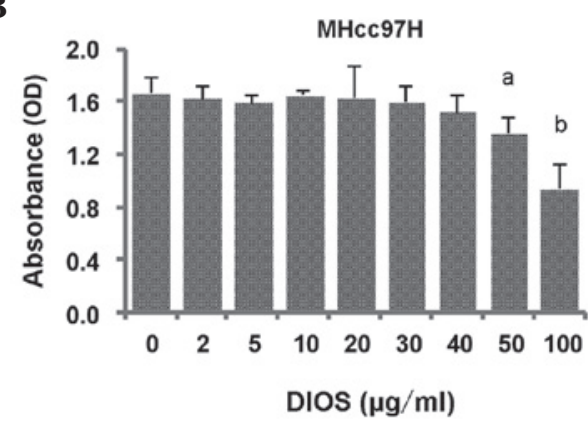

Figure 2. Concentrations of DIOS $<50 \mu \mathrm{g} / \mathrm{ml}$ has no inhibitory effect on the proliferation of SK-HEP-1 or MHcc $97 \mathrm{H}$ cells. Cell viability following treatment with different concentrations of DIOS for $24 \mathrm{~h}$ was detected using a 3-(4, 5-dimethylthiazol-2-yl)-2,5-diphenyltetrazolium bromide assay. (A) Absorbance in the SK-HEP-1 cells; (B) Absorbance in the MHcc97H cells. Each experiment was performed $\geq 3$ times and data are presented as the mean \pm standard error of the mean. ${ }^{a} \mathrm{P}<0.05,{ }^{b} \mathrm{P}<0.01$ and ${ }^{\mathrm{C}} \mathrm{P}<0.001$, vs. control. Data were analyzed using Student's $t$-test. DIOS, diosmetin; OD, optical density.

A

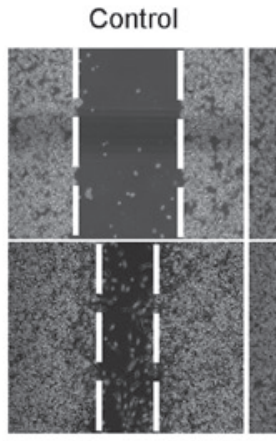

B

$\mathrm{Oh}$

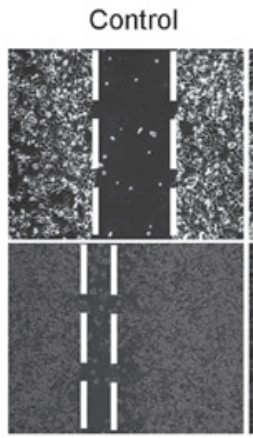

C

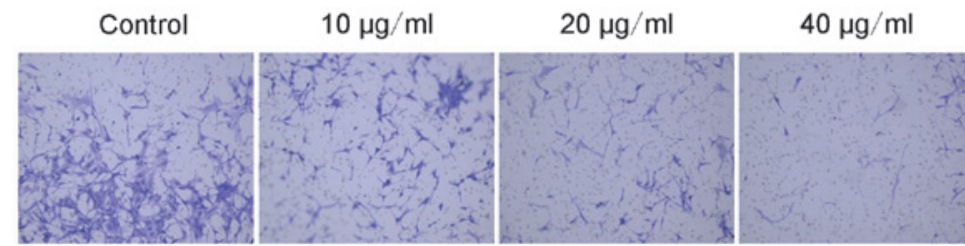

D

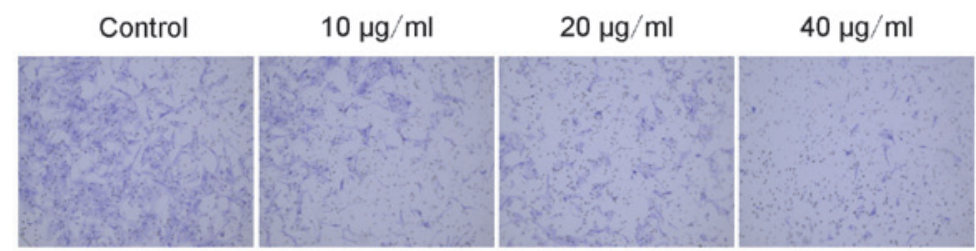

$20 \mu \mathrm{g} / \mathrm{ml}$

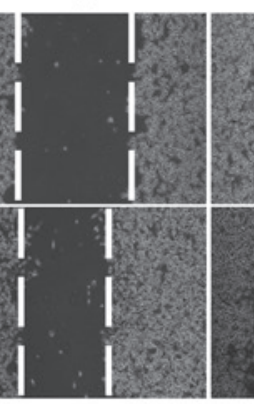

$10 \mu \mathrm{g} / \mathrm{ml}$
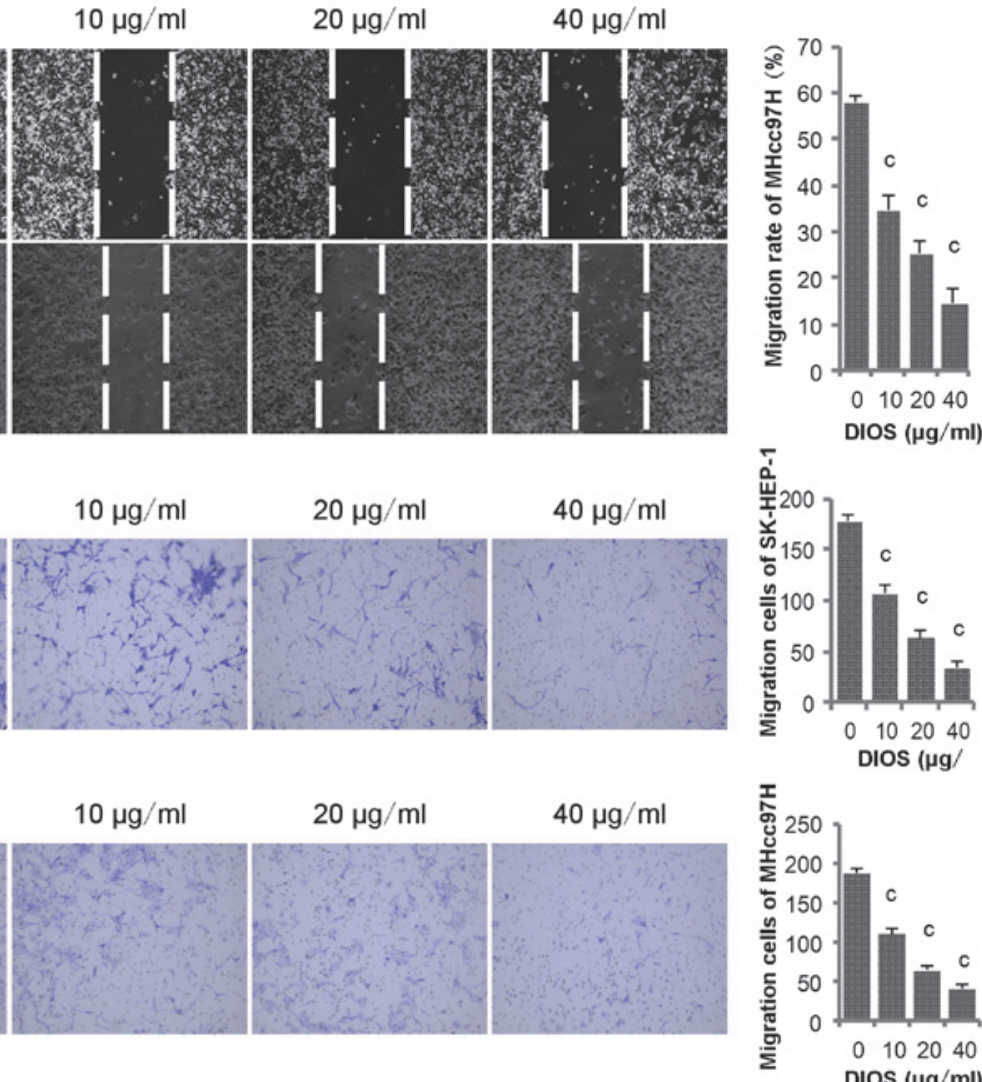

Figure 3. DIOS inhibits the migration of SK-HEP-1 and MHcc97H cells. (A) Results of the wound healing assay showed that DIOS treatment for 24 h inhibited the migration of SK-HEP-1 cells in a concentration-dependent manner. (B) Results of the wound healing assay of MHcc97H cells following treatment with different concentrations of DIOS for $24 \mathrm{~h}$. (C) Results of the cell motility assay of SK-HEP-1 cells following treatment with different concentrations of DIOS for $24 \mathrm{~h}$. (D) Results of the cell motility assay of MHcc97H cells following treatment with different concentrations of DIOS for $24 \mathrm{~h}$. Data are presented as the mean \pm standard error of the mean. Magnification, $100 \mathrm{x} .{ }^{\mathrm{c}} \mathrm{P}<0.001$, vs. $0 \mu \mathrm{g} / \mathrm{ml}$ (control). Data were analyzed using Student's t-test. DIOS, diosmetin. 
A

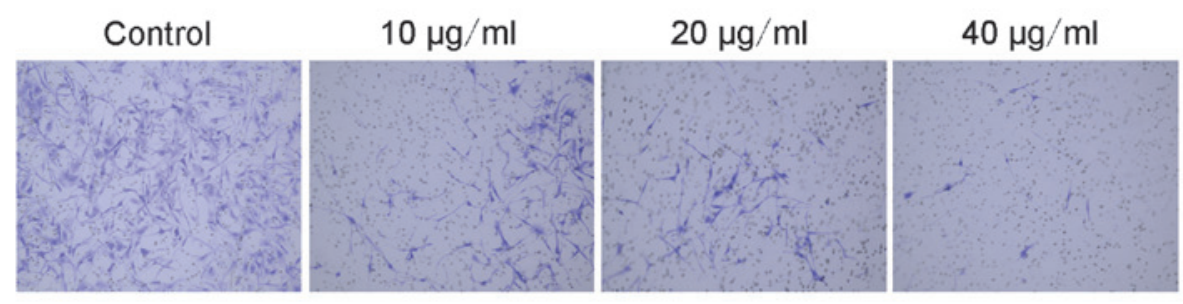

B Control

$10 \mu \mathrm{g} / \mathrm{ml}$

$20 \mu \mathrm{g} / \mathrm{ml}$

$40 \mu \mathrm{g} / \mathrm{ml}$
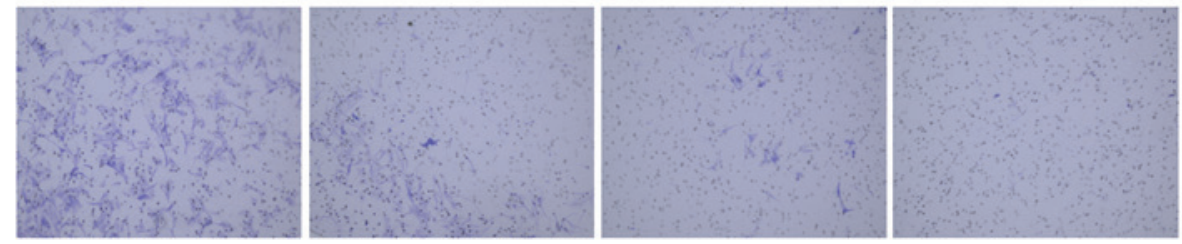

C

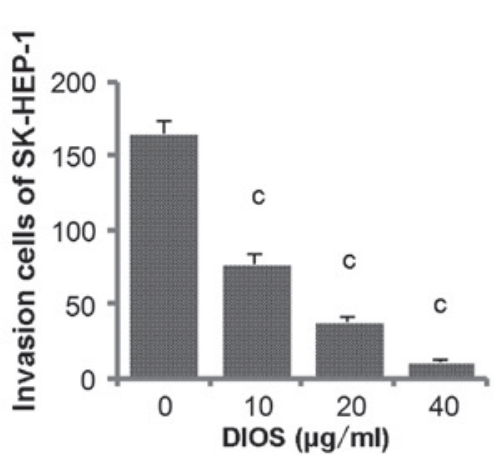

$\mathbf{E}$

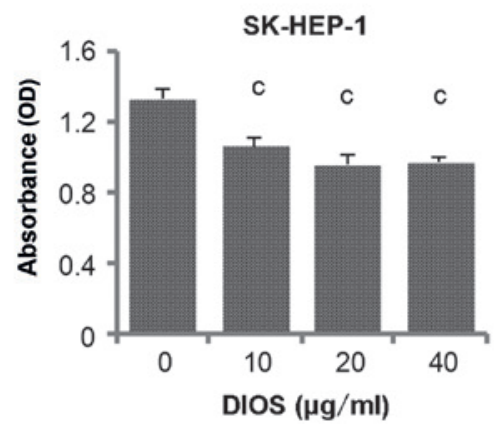

D

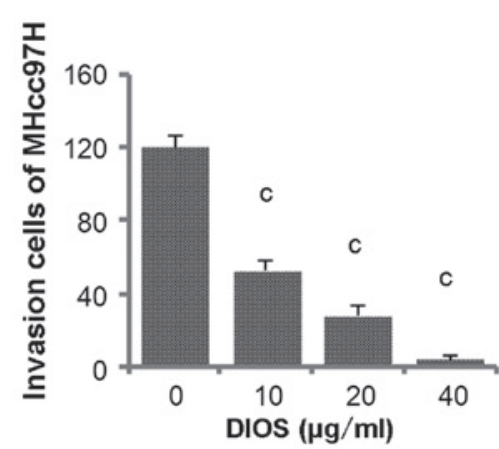

F

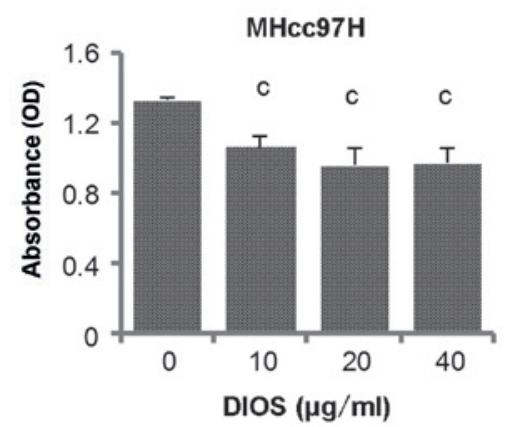

Figure 4. DIOS inhibits invasion and adhesion in SK-HEP-1 and MHcc97H cells. Results of invasion assays of the (A) SK-HEP-1 and (B) MHcc97H cells following treatment with different concentrations of DIOS for $24 \mathrm{~h}$. Quantification of the numbers of invaded cell in the (C) SK-HEP-1 and (D) MHcc97H cells. Absorbance of the (E) SK-HEP-1 and (F) MHcc97H cells using an adhesion assay. ${ }^{\mathrm{c}} \mathrm{P}<0.001$, vs. $0 \mu \mathrm{g} / \mathrm{ml}$ (control). Data were analyzed using Student's $\mathrm{t}$-test and are presented as the mean \pm standard error of the mean. DIOS, diosmetin; OD, optical density.

detected using western blotting, the protocol of which was as reported previously (14). Briefly, cells were seeded in $100 \mathrm{~mm}$ culture dishes at a density of $10^{5}$ cell $/ \mathrm{ml}$ in $10 \mathrm{ml}$ culture media and subsequently cultured at $37^{\circ} \mathrm{C}$ for $24 \mathrm{~h}$ in an atmosphere containing $5 \% \mathrm{CO}_{2}$. Subsequently, cells were exposed to various concentrations of DIOS $(0,10,20$ and $40 \mu \mathrm{g} / \mathrm{ml}$ and were washed in PBS twice and suspended in lysis buffer for $30 \mathrm{~min}$ on ice. Lysates were then centrifuged at 13,000 $\mathrm{x} \mathrm{g}$ at $4^{\circ} \mathrm{C}$ for $10 \mathrm{~min}$, separated by $10 \%$ sodium dodecyl sulfate-polyacrylamide gel electrophoresis and transferred onto polyvinylidene difluoride membranes (EMD Millipore, Billerica, MA, USA). The membranes were then blocked in Tris-buffered saline (Beyotime Institute of Biotechnology, Haimen, China) with $0.1 \%$ Tween 20 (Sangon Biotech Co., Ltd., Shanghai, China) (TBST), containing 5\% bovine serum albumin for $1 \mathrm{~h}$. The membranes were then incubated with the following rabbit anti-human primary antibodies at $4^{\circ} \mathrm{C}$ overnight: Anti-MMP-2 monoclonal antibody (mAb; 13132), anti-MMP-9 mAb (13667), anti-JNK polyclonal antibody (pAb; 9258), anti-p-JNK mAb (4668), anti-ERK1/2 mAb (4695), anti-p-ERK1/2 mAb (8544) and anti-PKC- $\delta$ pAb (all $1: 1,000 ; 2058)$. Following washing three times with TBST supplemented with $150 \mathrm{mM} \mathrm{NaCl}$ for $10 \mathrm{~min}$, the membranes were incubated with HRP-conjugated goat anti-rabbit immunoglobulin G secondary antibody (1:1,000; E030120-02) for $2 \mathrm{~h}$ at room temperature. Membranes were washed three times with TBST for $10 \mathrm{~min}$ and the bands were exposed in a dark room and analyzed using Alpha-view gradation analyzing system (Alpha View SA 3.4.0, ProteinSimple, Santa Clara, CA, USA). 
A

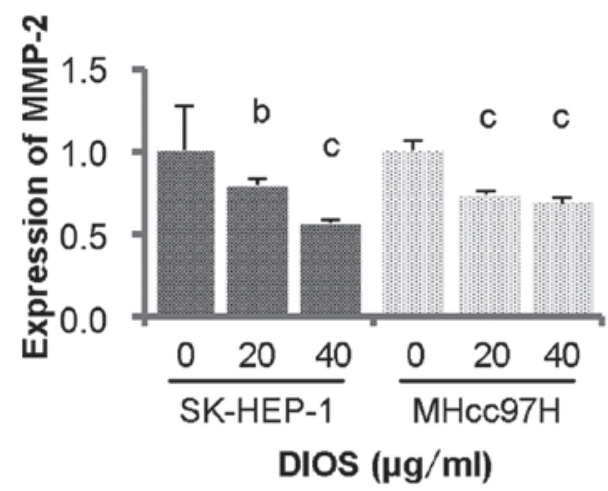

B

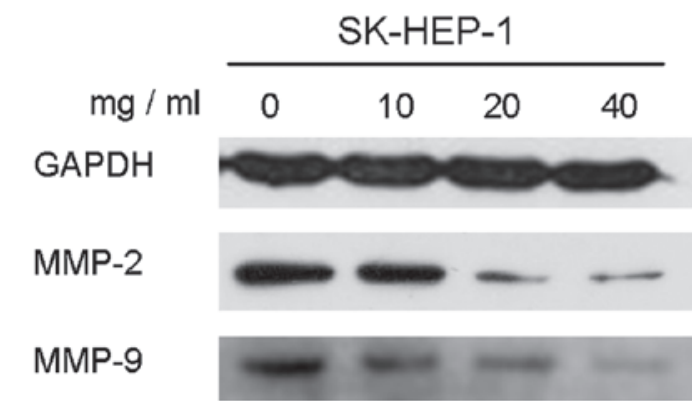

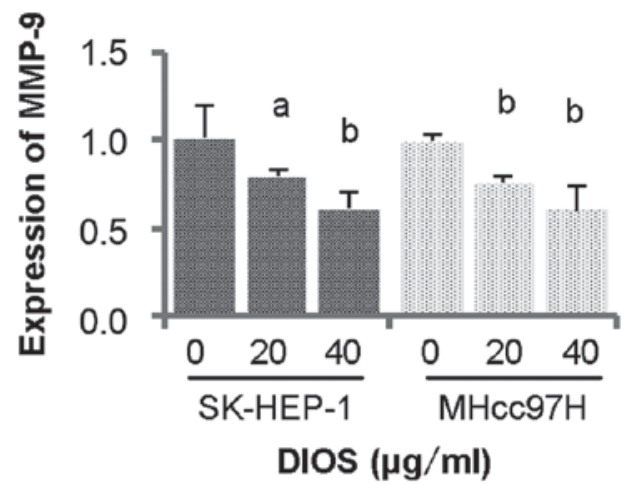

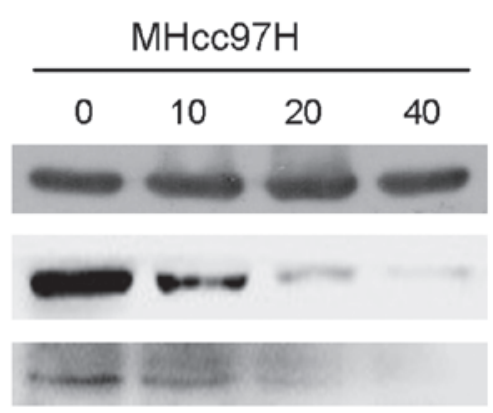

Figure 5. DIOS reduces the expression of MMP-2/9. (A) mRNA expression levels of MMP-2 and MMP-9 following treatment with different concentrations of DIOS for $24 \mathrm{~h}$ in SK-HEP-1 and MHcc97H cells. (B) Protein expression levels of MMP-2 and MMP-9 following treatment with different concentrations of DIOS for $24 \mathrm{~h}$ in SK-HEP-1 and MHcc97H cells. ${ }^{\mathrm{a}} \mathrm{P}<0.05$, ${ }^{\mathrm{b}} \mathrm{P}<0.01$ and ${ }^{\mathrm{C}} \mathrm{P}<0.001$, vs. $0 \mu \mathrm{g} / \mathrm{ml}$ (control). Data were analyzed using Student's t-test and are presented as the mean \pm standard error of the mean.. DIOS, diosmetin; MMP, matrix metalloproteinase.

Table I. Expression levels of related proteins following treatment with diosmetin (DIOS).

\begin{tabular}{|c|c|c|c|c|c|c|c|c|}
\hline \multirow[b]{2}{*}{ DIOS $(\mu \mathrm{g} / \mathrm{ml})$} & \multicolumn{4}{|c|}{ Expression levels of SK-HEP-1 } & \multicolumn{4}{|c|}{ Expression levels of $\mathrm{MHcc} 97 \mathrm{H}$} \\
\hline & 0 & 10 & 20 & 40 & 0 & 10 & 20 & 40 \\
\hline MMP-2 & 1.00 & 0.81 & 0.19 & 0.13 & 1.00 & 0.36 & 0.05 & 0.03 \\
\hline MMP-9 & 1.00 & 0.83 & 0.62 & 0.46 & 1.00 & 0.80 & 0.36 & 0.08 \\
\hline p38 & 1.00 & 1.02 & 1.14 & 0.81 & 1.00 & 0.88 & 0.70 & 0.78 \\
\hline p-p38 & 1.00 & 0.74 & 0.67 & 0.45 & 1.00 & 0.54 & 0.52 & 0.46 \\
\hline ERK $1 / 2$ & 1.00 & 1.06 & 1.13 & 0.87 & 1.00 & 0.94 & 0.85 & 0.83 \\
\hline p-ERK 1/2 (p44) & 1.00 & 1.13 & 0.56 & 0.70 & 1.00 & 0.62 & 0.57 & 0.24 \\
\hline p-ERK 1/2 (p42) & 1.00 & 0.80 & 0.64 & 0.76 & 1.00 & 0.75 & 0.41 & 0.11 \\
\hline JNK (p54) & 1.00 & 0.78 & 0.80 & 0.63 & 1.00 & 0.92 & 0.86 & 0.52 \\
\hline JNK (p46) & 1.00 & 0.91 & 0.95 & 0.73 & 1.00 & 0.77 & 0.62 & 0.46 \\
\hline p-JNK (p54) & 1.00 & 0.79 & 0.70 & 0.54 & 1.00 & 0.57 & 0.24 & 0.19 \\
\hline p-JNK (p46) & 1.00 & 1.12 & 0.98 & 0.59 & 1.00 & 0.67 & 0.55 & 0.07 \\
\hline PKC- $\delta$ & 1.00 & 0.81 & 0.75 & 0.57 & 1.00 & 0.97 & 0.29 & 0.43 \\
\hline
\end{tabular}

MMP, matrix metalloproteinase; ERK, extracellular signal-regulated kinase; JNK, c-Jun N-terminal kinase; PKC, protein kinase C.

Statistical analysis. Data were obtained from $\geq 3$ independent experiments and all results are presented as the mean \pm standard error of the mean. Between-group differences were assessed via Student's t-test using SPSS 18.0 (SPSS, Inc., Chicago, IL, USA). Comparisons were relative to untreated controls. $\mathrm{P}<0.05$ was considered to indicate a statistically significant difference.

\section{Results}

DIOS does not inhibit cell proliferation at a low concentration. MTT assays were performed to investigate the inhibitory ability of DIOS on the proliferation of SK-HEP-1 and MHcc97H cells. As shown in Fig. 2, the SK-HEP-1 and $\mathrm{MHcc} 97 \mathrm{H}$ cells were treated with various concentrations of 


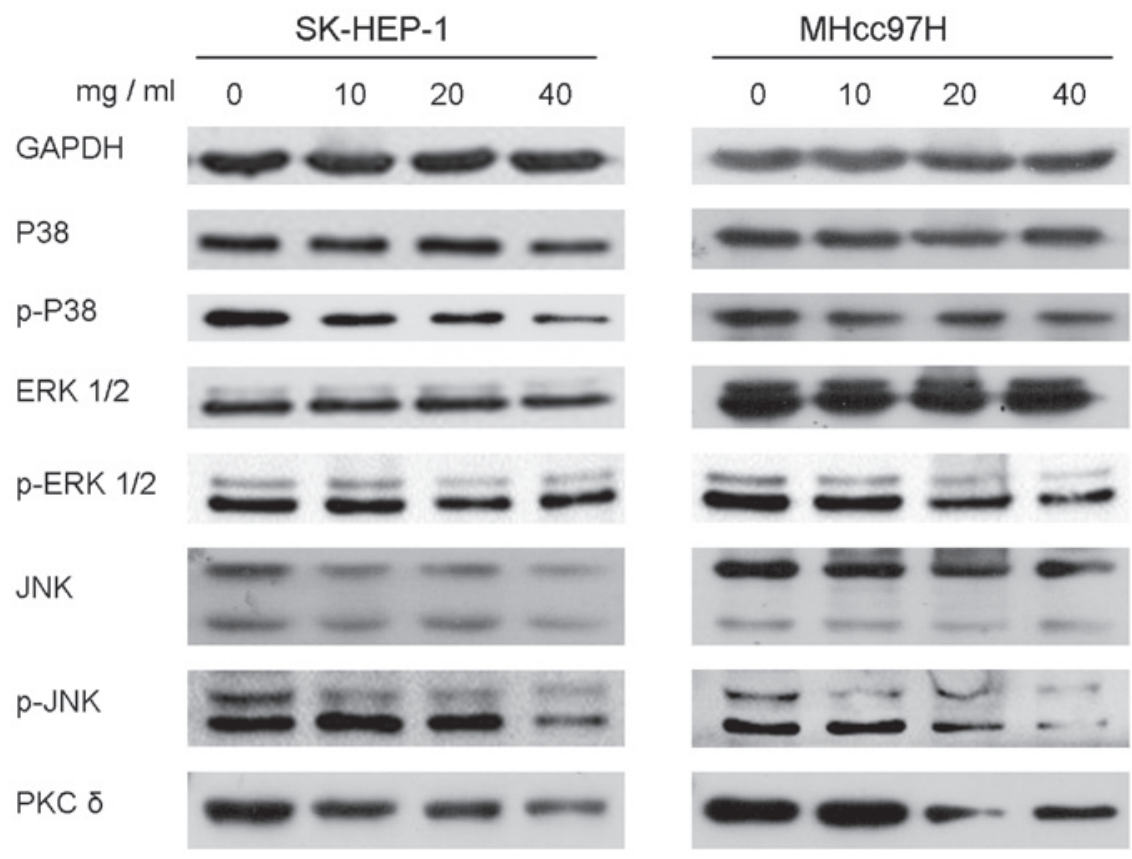

Figure 6. DIOS regulates the PKC- $\delta$ and mitogen-activated protein kinase pathways. DIOS, diosmetin.; p-, phosphoylated; ERK, extracellular signal-regulated kinase; JNK, c-Jun N-terminal kinase; PKC, protein kinase C.

DIOS for $24 \mathrm{~h}$, however, cell proliferation was not affected by DIOS until the concentration reached $50 \mu \mathrm{g} / \mathrm{ml}$ for the MHcc $97 \mathrm{H}$ cells $(\mathrm{P}<0.05)$ and $100 \mu \mathrm{g} / \mathrm{ml}$ for the SK-HEP-1 cells $(\mathrm{P}<0.001)$.

DIOS inhibits the migration of SK-HEP-1 and MHcc $97 \mathrm{H}$ cells. The role of DIOS in HCC metastasis was also investigated using a wound healing assay and cell motility assay. Initially, to identify whether the effect of DIOS on HCC occurred due the inhibition of cell proliferation or metastatic suppression, the SK-HEP-1 and MHcc97H cells were treated with 10,20 and $40 \mathrm{mg} / \mathrm{ml}$ DIOS. As described above, the results of the previous MTT assay showed that these concentrations had no effect on cell proliferation. In the wound healing assay, the width of the wounds were measured at $0 \mathrm{~h}$ and at $24 \mathrm{~h}$ post-DIOS treatment and migration rates were calcuated. The results are shown in Fig. 3, in which the migration rates of the SK-HEP-1 and MHcc97H cells were $>50 \%$ higher, compared with those in the control groups $24 \mathrm{~h}$ post-wounding. However, the migration rate was significantly reduced in the groups treated with DIOS, which occurred in a dose-dependent manner (Fig. $3 \mathrm{~A}$ and $\mathrm{B}$; $\mathrm{P}<0.001$ ). In the cell motility assay, the cells which passed though the porous polycarbonate membranes were counted to assess whether DIOS affected the migration of the SK-HEP-1 and $\mathrm{MHcc} 97 \mathrm{H}$. The results showed that fewer cells passed though the membranes of the Transwell chambers following DIOS treatment (Fig. 3C and D; $\mathrm{P}<0.001$ ). The results of the wound healing and cell motility assays indicated that DIOS significantly inhibited the migration of the SK-HEP-1 and MHcc97H HCC cells.

DIOS inhibits the invasion of SK-HEP-1 and MHcc $97 H$ cells. In the present study, tumor aggressiveness was evaluated using a basement membrane invasion assay. The cells observed to degrade the Matrigel and pass through the porous polycarbonate membranes were counted, and the results revealed that DIOS efficiently inhibited the invasion of the SK-HEP-1 and MHcc97H cells across the membranes pretreated with Matrigel. The numbers of cells on the lower surface of the membranes decreased in a dose-dependent manner following DIOS treatment (Fig. 4A and D; $\mathrm{P}<0.001$ ). These results indicated that DIOS significantly inhibited HCC cell invasion.

DIOS reduces the adherence abilities of SK-HEP-I and MHcc $97 \mathrm{H}$ cells. Cancer cell metastasis involves multiple processes, including migration, adhesion and invasion, and the adherence of cells to the ECM or the basement membrane is a crucial step during cancer invasiveness (3). In the present study, the adherence abilities of the SK-HEP-1 and MHcc97H cell lines were significantly reduced following DIOS pretreatment (Fig. 4E and F; $\mathrm{P}<0.001$ ). These results indicated that DIOS effectively inhibited the adherence ability of the SK-HEP-1 and MHcc97H cells.

DIOS downregulates the expression levels of MMP-2 and $M M P-9$ in SK-HEP-1 and MHcc97H cells. It is known that MMPs are key enzymes involved in degradation of the ECM, and that MMP-2 and MMP-9 are important in cancer invasion and metastasis (3). To determine the effect of DIOS on HCC cell metastasis, the expression levels of MMP-2/9 were detected using RT-qPCR and Western blot analyses. The results demonstrated that the expression levels of MMP-2/9 were significantly reduced following DIOS treatment (Fig. 5A and $\mathrm{B} ; \mathrm{P}<0.05)$.

Downregulation of MMP-2/9 by DIOS is associated with the MAPK and PKC- $\delta$ pathways. The present study further investigated the mechanism underlying the inhibitory effect 
of DIOS on HCC metastasis. MAPK and PKC- $\delta$ pathway proteins, including P38, ERK 1/2, JNK, PKC- $\delta$ and their phosphorylated forms, were measured using Western blotting. DIOS treatment for $24 \mathrm{~h}$ had no effect on the protein levels of P38 in the SK-HEP-1 or MHcc97H cell lines, however, the levels of the phosphorylated form, p-P38, were markedly decreased. DIOS treatment for $24 \mathrm{~h}$ markedly reduced the protein expression levels of ERK 1/2 and JNK, and markedly reduced the protein levels of p-ERK $1 / 2$ and p-JNK. The results showed that DIOS also downregulated the protein levels of PKC- $\delta$ (Fig. 6).

\section{Discussion}

$\mathrm{HCC}$ is one of most malignant types of tumor and a major common cause of cancer-associated mortality. Several traditional Chinese medicines have been reported for their antitumor properties, including baicalein (15), dihydromyricetin $(2,7,16)$ and resveratrol (17). As a flavonoids compound, DIOS has several medicinal properties, including antibacterial, antimicrobial anti-inflammatory and antioxidant effects (12). Although a previous study demonstrated that DIOS induces cell cycle arrest of HCC cells (18), the role of DIOS on the metastasis of HCC cells remains to be fully elucidated. The metastasis of cancer involves complex processes, including migration and invasion through the tumor stroma, intravasation, tumor cell dissemination, extravasation and cell growth at metastatic sites (19). The present study showed that DIOS inhibited the migration, invasion and adhesion of SK-HEP-1 and MHcc97H cells, which demonstrated that DIOS effectively suppressed the metastasis of SK-HEP-1 and MHcc97H cells.

MMPs are a family of proteolytic enzymes, which have a number of important physiological roles, including ECM modification, accelerating cell migration and cleaving cytokines (20). In the MMP family, MMP-2/9 are reported as substrate-specific gelatinases, which are critical in ECM degradation $(12,21)$. Elevated levels of MMP-2/9 correlate with invasion, metastasis and poor prognosis in various types of cancer $(22,23)$. Therefore, the suppression of MMP-2/9, is an important strategy to prevent cancer cell invasion (24). In the present study, MMP-2 and MMP-9 were downregulated following DIOS treatment for $24 \mathrm{~h}$, in the SK-HEP-1 and MHcc97H cells. This result indicated that DIOS suppressed the metastasis of the SK-HEP-1 and $\mathrm{MHcc} 97 \mathrm{H}$ cells through inhibition of the expression of MMP-2/9.

It has been observed previously that members of the MAPK family, including p38 MAPK, ERK $1 / 2$ and JNK, are activated in several types of cancer $(25,26)$. There is increasing evidence that the MAPK family is involved in the migration and invasion of cancer, and that all three of the proteins mentioned above regulate the expression of MMPs $(23,27,28)$. To investigate whether the downregulation of MMP-2 and MMP-9 is associated with the MAPK family, the expression levels of p38, ERK 1/2 and JNK, and their phosphorylated forms, were detected using Western blotting. The data demonstrated no significant change in the the expression levels of p38 and ERK 1/2, however, the phosphorylations of p38 and ERK decreased significantly in the SK-HEP-1 and MHcc97H cells. The expression levels of JNK and p-JNK were downregulated significantly in the SK-HEP-1 and MHcc97H cells. These results suggested that the MAPK family (p38 MAPK, ERK 1/2 and JNK) was important in the DIOS-mediated cell metastasis.

The upstream protein of ERK is PKC, which is a family of intracellular protein kinases that activate serine/threonine kinases, including MAPK, nuclear factor $\kappa \mathrm{B}$ and phosphatidylinositol-3-kinase by controlling the growth, migration and death of cells, and several PKCs are considered to be associated with tumor progression (23). It has been reported that PKC- $\delta$ is overexpressed in human ductal carcinoma (29). The inhibition of PKC- $\delta$ may suppress the migration of cells through the PKC/ERK/MMP-9 pathways (30-32). In the present study, PKC- $\delta$ was downregulated following DIOS treatment for $24 \mathrm{~h}$ in the SK-HEP-1 and MHcc97H cells, which indicated that DIOS inhibited the metastasis of the SK-HEP-1 and MHcc97H cell via the PKC/MAPK/MMPs pathways.

In conclusion, the results of the present study showed that DIOS inhibited the migration, invasion and adhesion of HCC cells by decreasing the gene and protein expression levels of MMP-2/9. Furthermore, the decreased expression of MMP-2/9 was regulated by the PKC- $\delta / M A P K / M M P s$ pathways. These results suggested that DIOS has a potent antimetastatic effect on HCC cells.

\section{Acknowledgements}

This study was supported, in part, by grants from the Special Funds from Education Department of Guangdong Province (grant no. JB1212), the Chinese NSFC grants (grant no. 31370824), the Yangfan Plan of Talents Recruitment Grant, Guangdong, China (grant no. YueRenCaiBan [2014] 1), the University Talents Recruitment Grant of Guangdong, China (grant no. YueCaiJiao [2012] 328) and The Excellent Postgraduate Essay Development Project of Guangdong Medical College (grant no. 2014-18).

\section{References}

1. Feng M, Gao W, Wang R, Chen W, Man YG, Figg WD, Wang XW, Dimitrov DS and Ho M: Therapeutically targeting glypican-3 via a conformation-specific single-domain antibody in hepatocellular carcinoma. Proc Natl Acad Sci USA 110: E1083-E1091, 2013.

2. Zhang Q, Liu J, Liu B, Xia J, Chen N, Chen X, Cao Y, Zhang C, Lu C, Li M and Zhu R: Dihydromyricetin promotes hepatocellular carcinoma regression via a p53 activation-dependent mechanism. Sci Rep 4: 4628, 2014.

3. Zhang QY, Li R, Zeng GF, Liu B, Liu J, Shu Y, Liu ZK, Qiu ZD, Wang DJ, Miao HL, et al: Dihydromyricetin inhibits migration and invasion of hepatoma cells through regulation of MMP-9 expression. World J Gastroenterol 20: 10082-10093, 2014.

4. Hsieh MJ, Lin CW, Yang SF, Chen MK and Chiou HL: Glabridin inhibits migration and invasion by transcriptional inhibition of matrix metalloproteinase 9 through modulation of NF- $\kappa \mathrm{B}$ and AP-1 activity in human liver cancer cells. Br J Pharmacol 171: 3037-3050, 2014.

5. Chen TY, Li YC, Liu YF, Tsai CM, Hsieh YH, Lin CW, Yang SF and Weng CJ: Role of MMP14 gene polymorphisms in susceptibility and pathological development to hepatocellular carcinoma. Ann Surg Oncol 18: 2348-2356, 2011.

6. Alexander SP, Benson HE, Faccenda E, Pawson AJ, Sharman JL, McGrath JC, Catterall WA, Spedding M, Peters JA, Harmar AJ, et al: The Concise Guide to PHARMACOLOGY 2013/14: Overview. Br J Pharmacol 170: 1449-1458, 2013.

7. Spanakis M, Kasmas S and Niopas I: Simultaneous determination of the flavonoid aglycones diosmetin and hesperetin in human plasma and urine by a validated GC/MS method: In vivo metabolic reduction of diosmetin to hesperetin. Biomed Chromatogr 23: 124-131, 2009. 
8. Chan BC, Ip M, Gong H, Lui SL, See RH, Jolivalt C, Fung KP, Leung PC, Reiner NE and Lau CB: Synergistic effects of diosmetin with erythromycin against $\mathrm{ABC}$ transporter over-expressed methicillin-resistant Staphylococcus aureus 1 (MRSA) RN4220/pUL5054 and inhibition of MRSA pyruvate kinase. Phytomedicine 20: 611-614, 2013.

9. Meng JC, Zhu QX and Tan RX: New antimicrobial mono-and sesquiterpenes from Soroseris hookeriana subsp. erysimoides. Planta Med 66: 541-544, 2000.

10. Chandler D, Woldu A, Rahmadi A, Shanmugam K, Steiner N Wright E, Benavente-García O, Schulz O, Castillo J and Münch G: Effects of plant-derived polyphenols on TNF-alpha and nitric oxide production induced by advanced glycation endproducts. Mol Nutr Food Res 54 (Suppl 2): S141-S150, 2010.

11. Liao W, Ning Z, Chen L, Wei Q, Yuan E, Yang J and Ren J: Intracellular antioxidant detoxifying effects of diosmetin on 2,2-azobis (2-amidinopropane) dihydrochloride (AAPH)-induced oxidative stress through inhibition of reactive oxygen species generation. J Agric Food Chem 62: 8648-8654, 2014.

12. Androutsopoulos VP, Mahale S, Arroo RR and Potter G: Anticancer effects of the flavonoid diosmetin on cell cycle progression and proliferation of MDA-MB 468 breast cancer cells due to CYP1 activation. Oncol Rep 21: 1525-1528, 2009.

13. Livak KJ and Schmittgen TD: Analysis of relative gene expression data using real-time quantitative PCR and the $2^{-\Delta \Delta C}$ method. Methods 25: 402-408, 2001

14. Liu J, Shu Y, Zhang Q, Liu B, Xia J, Qiu M, Miao H, Li M and Zhu R: Dihydromyricetin induces apoptosis and inhibits proliferation in hepatocellular carcinoma cells. Oncol Lett 8 : 1645-1651, 2014.

15. Chen H, Gao Y, Wu J, Chen Y, Chen B, Hu J and Zhou J: Exploring therapeutic potentials of baicalin and its aglycone baicalein for hematological malignancies. Cancer Lett 354 5-11, 2014.

16. Zeng G, Liu J, Chen H, Liu B, Zhang Q, Li M and Zhu R: Dihydromyricetin induces cell cycle arrest and apoptosis in melanoma SK-MEL-28 cells. Oncol Rep 31: 2713-2719, 2014.

17. Liu B, Zhou Z, Zhou W, Liu J, Zhang Q, Xia J, Liu J, Chen N, Li M and Zhu R: Resveratrol inhibits proliferation in human colorectal carcinoma cells by inducing G1/S-phase cell cycle arrest and apoptosis through caspase/cyclin-CDK pathways. Mol Med Rep 10: 1697-1702, 2014.

18. Androutsopoulos VP and Spandidos DA: The flavonoids diosmetin and luteolin exert synergistic cytostatic effects in human hepatoma HepG2 cells via CYP1A-catalyzed metabolism, activation of JNK and ERK and P53/P21 up-regulation. J Nutr Biochem 24: 496-504, 2013

19. Kwon M, Lee SJ, Wang Y, Rybak Y, Luna A, Reddy S, Adem A, Beaty BT, Condeelis JS and Libutti SK: Filamin A interacting protein 1-like inhibits WNT signaling and MMP expression to suppress cancer cell invasion and metastasis. Int J Cancer 135 48-60, 2014.
20. Elkington PT and Friedland JS: Matrix metalloproteinases in destructive pulmonary pathology. Thorax 61: 259-266, 2006.

21. Chen T, Li M, Zhang R and Wang H: Dihydroartemisinin induces apoptosis and sensitizes human ovarian cancer cells to carboplatin therapy. J Cell Mol Med 13: 1358-1370, 2009.

22. Hurst DR and Welch DR: Metastasis suppressor genes at the interface between the environment and tumor cell growth. Int Rev Cell Mol Biol 286: 107-180, 2011.

23. Lin CW, Shen SC, Chien CC, Yang LY, Shia LT and Chen YC: 12-O-tetradecanoylphorbol-13-acetate-induced invasion/migration of glioblastoma cells through activating PKCalpha/ERK/NF-kappaB-dependent MMP-9 expression. J Cell Physiol 225: 472-481, 2010.

24. Hidalgo $\mathrm{M}$ and Eckhardt SG: Development of matrix metalloproteinase inhibitors in cancer therapy. J Natl Cancer Inst 93 178-193, 2001

25. Hwang YP, Yun HJ, Kim HG, Han EH, Lee GW and Jeong HG: Suppression of PMA-induced tumor cell invasion by dihydroartemisinin via inhibition of PKCalpha/Raf/MAPKs and NF-kappaB/AP-1-dependent mechanisms. Biochem Pharmacol 79: 1714-1726, 2010.

26. He Q, Zhou X, Li S, Jin Y, Chen Z, Chen D, Cai Y, Liu Z, Zhao T and Wang A: MicroRNA-181a suppresses salivary adenoid cystic carcinoma metastasis by targeting MAPK-Snai2 pathway. Biochim Biophys Acta 1830: 5258-5266, 2013.

27. Woo JH, Lim JH, Kim YH, Suh SI, Min DS, Chang JS, Lee YH, Park JW and Kwon TK: Resveratrol inhibits phorbol myristate acetate-induced matrix metalloproteinase-9 expression by inhibiting JNK and PKC delta signal transduction. Oncogene 23: $1845-1853,2003$

28. Reunanen N, Westermarck J, Häkkinen L, Holmström TH, Elo I, Eriksson JE and Kähäri VM: Enhancement of fibroblast collagenase (matrix metalloproteinase-1) gene expression by ceramide is mediated by extracellular signal-regulated and stress-activated protein kinase pathways. J Biol Chem 273: 5137-5145, 1998.

29. Mauro LV, Grossoni VC, Urtreger AJ, Yang C, Colombo LL, Morandi A, Pallotta MG, Kazanietz MG, Bal de Kier Joffé ED and Puricelli LL: PKC Delta (PKCdelta) promotes tumoral progression of human ductal pancreatic cancer. Pancreas 39: e31-e41, 2010.

30. Hu CT, Cheng CC, Pan SM, Wu JR and Wu WS: PKC mediates fluctuant ERK-paxillin signaling for hepatocyte growth factor-induced migration of hepatoma cell HepG2. Cell Signal 25: 1457-1467, 2013.

31. Hu CT, Wu JR, Cheng CC, Wang S, Wang HT, Lee MC, Wang LJ, Pan SM, Chang TY and Wu WS: Reactive oxygen species-mediated PKC and integrin signaling promotes tumor progression of human hepatoma HepG2. Clin Exp Metastasis 28: 851-863, 2011.

32. Hsieh HL, Wu CY and Yang CM: Bradykinin induces matrix metalloproteinase-9 expression and cell migration through a PKC-delta-dependent ERK/Elk-1 pathway in astrocytes. Glia 56: 619-632, 2008 